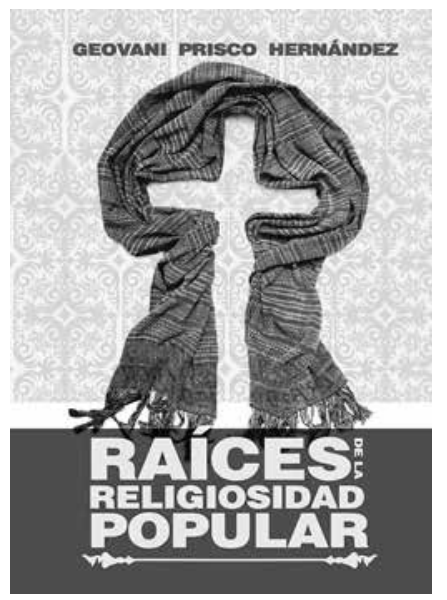

- Raíces de la religiosidad popular

Geovani Prisco Hernández, 2016

Gobierno del Estado de Tlaxcala/

Consejo Nacional para la Cultura

y las Artes/Instituto Tlaxcalteca

de la Cultura/Programa de Apoyo

a las Culturales Municipales y

Comunitarias, México

Popular Religion and

Ceremonial Speeches in Nahua Communities of the Edge of the Matlalcueyetzin, Tlaxcala

PARAstoo Anita MesRI

HASHEMI-DILMAGHANI

El Colegio de Tlaxcala, San Pablo

Apetatitlán, Tlaxcala, México

parastooanita@yahoo.com.mx

Desacatos 58 , septiembre-diciembre 2018, pp. 214-218

\section{Religiosidad popular y discursos ceremoniales en las comunidades nahuas de las faldas de la Matlalcueyetzin, Tlaxcala}

\author{
PARASTOO ANITA MESRI HASHEMI-DILMAGHANI
}

ro de Geovani Prisco Hernández habla del lenguaje relacionado con la religiosidad popular en la comunidad nahua de San Pablo del Monte, Cuauhtotoatla, ubicada en las faldas del volcán la Matlalcueyetzin, en el Sureste de Tlaxcala. El autor, originario de la comunidad, presenta su investigación en cinco capítulos, antecedidos por una introducción y conclusiones generales como cierre.

La relevancia del trabajo de Prisco Hernández se fundamenta en su descripción de los elementos definitorios de la vida colectiva de una comunidad ubicada en la región que más conserva las culturas nahua y otomí tlaxcaltecas en la actualidad. Aunque su enfoque es la religiosidad propia y el lenguaje utilizado en este ámbito, da testimonio de varias instituciones comunitarias que definen a las comunidades de la región, en la que el paisaje cultural es dominado por la presencia de la montaña sagrada. 
En particular, la importancia de la religiosidad popular como elemento cultural en las comunidades nahuas de la región de la Matlalcueyetzin se observa con facilidad, y al adentrarse en su vida colectiva, se hace más patente aún. El tema es producto de diversos procesos históricos marcados por la invasión de los españoles y la lucha para sobrevivir como comunidades diferenciadas.

En la actualidad, lo que ahora se considera "religiosidad popular" es una parte esencial de la forma de organización y sistemas normativos indígenas vigentes en Tlaxcala. Se trata de una esfera de conservación de poder sobre la vida colectiva y de identidades comunitarias unificadoras, en el contexto colonial, y hoy, de colonialismo interno. En palabras de Johanna Broda: "los santos asumieron un papel fundamental como protectores y patrones de gremios y oficios, de cofradías y congregaciones novohispanas; se convirtieron en símbolo corporativo y factor de cohesión" (2009: 12-13).

Lo que diferencia el trabajo de Prisco Hernández es su enfoque en el lenguaje utilizado en el contexto de la religiosidad popular propia de su comunidad. Es un campo poco explorado por la antropología y la lingüística en México.

Para lograr un tratamiento amplio del tema, en el primer capítulo, titulado "Marco socio-espacial, histórico y cultural de San Pablo del Monte", presenta un mapeo de la comunidad que incluye su ubicación geográfica, el origen de su nombre antiguo, Cuauhtotoatla, y su organización sociorreligiosa basada en los barrios, que originalmente fueron cuatro y ahora son 12 (p. 17).

Como parte de su descripción del contexto sociopolítico de la comunidad, menciona que San Pablo del Monte tiene como autoridades un sacerdote, un presidente municipal y un fiscal, y que "todos estos agentes son complementarios" (p. 13). En cuanto a los fiscales, anota que las fiscalías "se fundaron en el siglo XVI por los franciscanos para tener en los pueblos personal indígena que se encargara de la difusión y mantenimiento de la evangelización" (p. 13, nota 1).

Su descripción de estas tres autoridades complementarias difiere de lo que se vive en otras comunidades nahuas de la región de la Matlalcueyetzin, en particular, las que no son sede parroquial. Por ejemplo, en San Felipe Cuauhtenco, perteneciente al municipio de Contla de Juan Cuamatzi, la parroquia está en la cabecera municipal, Contlan o San Bernardino Contla, y el sacerdote tiene poca presencia en la comunidad. No se considera una autoridad comunitaria, mucho menos complementaria del fiscal o el presidente de comunidad, denominación que recibe la autoridad civil en comunidades que no son cabeceras municipales en Tlaxcala.

Prisco Hernández reconoce que, en el caso de San Pablo del Monte, "la religiosidad popular opera con o sin el sacerdote” (p. 25), pues está a cargo de los fiscales y mayordomos, conocidos en su conjunto como la cofradía en Cuauhtenco. Además, al igual que en San Pablo del Monte, en Cuauhtenco hay rezanderos que saben "en qué momento rezar, cantar y animar al pueblo para que ellos también lo hagan” (p. 25).

En el tema de la organización sociorreligiosa de la comunidad, los cargos religiosos - fiscales, mayordomos - se rotan entre los 12 barrios que conforman la comunidad (pp. 17, 28). Esto también ocurre en otras comunidades nahuas grandes de la región, como San Francisco Tetlanohcan, donde los cargos se turnan entre los tres barrios (entrevista con Alfonso Cuatianquiz Garza, San Francisco Tetlanohcan, 27 de octubre de 2016). ${ }^{1}$

En la misma descripción de la organización sociorreligiosa comunitaria, Prisco Hernández hace referencia a las procesiones, una institución propia, de mucha importancia no sólo en San Pablo del Monte, sino en toda la región de la Matlalcueyetzin. Nazario

1

Al momento de las entrevistas, Cuatianquiz tenía el cargo de fiscal, máxima autoridad religiosa de la comunidad. 
Sánchez Mastranzo, investigador del Centro del Instituto Nacional de Antropología e Historia-Tlaxcala, también originario de la comunidad, formuló la siguiente definición de esta institución:

La procesión es una marcha ritual de imágenes y de personas, pero en un escenario local, según normas preestablecidas y siguiendo un camino parabólico cuyos puntos de partida y llegada coinciden siempre o al menos resultan equivalentes. La procesión puede ser un rito de distinción, de apropiación o de celebración (2004: 16-17).

Es necesario analizar el tema desde la cosmovisión y realidad propia del pueblo nahua, que no concibe el mundo y los sucesos como lineales, sino circulares, o como un conjunto de espirales en diferentes planos. En esta realidad, afirma Sánchez, "todo se reduce a describir un círculo que reconduce siempre al punto de partida, como si nada se hubiera movido realmente" (2004: 17).

En el segundo capítulo, dedicado al marco teórico, Prisco Hernández hace referencia a la propuesta de Luis Fernando Lara, que se explica en su Curso de lexicología (2006) y que plantea que el léxico de una lengua está unido indisociablemente a la cultura (p. 35). Los discursos ceremoniales y formas de hablar relacionadas con la religiosidad popular en San Pablo del Monte, como otros elementos culturales de la comunidad, se aprenden dentro de la misma colectividad, "al observar a los padres realizar estas ceremonias, de tal manera que cuando toca ejercer dichos cargos, se espera que se conozca qué hacer" (p. 37). Este capítulo termina con la aclaración de que el objetivo de la investigación es contribuir al reconocimiento de la religiosidad popular como parte de la tradición oral del español de México (p. 39).

Así como la procesión, el discurso ceremonial o quimati tlahtos — saber hablar- es una institución de suma importancia en diversas comunidades de la región de la Matlalcueyetzin, tanto dentro del ciclo ritual como en varios momentos de la vida cotidiana. Un ámbito del gobierno comunitario en el que es imprescindible "saber hablar", como dicen en San Felipe Cuauhtenco, es el cabildo eclesiástico. Esto ubica la relevancia del estudio del lenguaje de Prisco Hernández en un ámbito marcadamente ceremonial, ritual y simbólico en la vida colectiva de las comunidades de la zona.

En el tercer capítulo, el autor explica su método de trabajo, que incluyó documentación etnográfica, con observación participante, facilitada en gran medida por ser originario y vecino de la comunidad. Sirve como ejemplo de la importancia de que las personas que pertenecen a las comunidades realicen estudios sobre los elementos que definen la vida comunitaria y la cultura.

El cuarto capítulo trata de una descripción del léxico de la religiosidad popular de San Pablo del Monte. Como parte de esta discusión, Prisco Hernández define a los actores clave de la autoridad religiosa comunitaria o el sistema de cargos religiosos. El mayordomo, explica, es quien tiene a su cargo y resguardo una imagen. El fiscal gobierna y preside las reuniones de los mayordomos (p. 54). También identifica términos usados en las prácticas religiosas, como "ir a rogar" - pedir el favor a una persona para que acepte ser mayordomo- o ser presentado - comunicar a los fiscales y mayordomos quién será el próximo mayordomo- (p. 57).

Es pertinente subrayar la importancia de los fiscales. Esta figura, en las comunidades nahuas tlaxcaltecas, fue descrita por Romano y Tolteca en estos términos: "es en muchos sentidos el eje regulador de la vida social y cultural de los pueblos en la región sur tlaxcalteca. Tal es su importancia que ha permanecido durante los últimos cuatrocientos cincuenta años resguardando repositorios que están bajo su responsabilidad" (2014: 37).

Por la institución del barrio, ya descrita como base de la vida comunitaria en San Pablo del Monte, 
existen dos niveles de mayordomos o gobiernos sociorreligiosos: el del barrio y el del pueblo. En el sistema de rotación barrial, cada mayordomía regresa al barrio cada diez años, lo mismo que el nombramiento del primer fiscal. El barrio decide a quiénes colocar en las mayordomías y fiscalías (p. 55).

De forma parecida, en San Francisco Tetlanohcan, donde también subsiste la institución del barrio como base de la organización comunitaria, existe una estructura de autoridades religiosas comunitarias, con sede en la iglesia que sirve de parroquia, y otra en cada barrio. Aparte de los cargos de la cofradía comunitaria en los que participan por turno, en cada barrio hay tres mayordomos responsables de la celebración de su imagen. De igual manera, dos de los barrios tienen cuatro fiscales (entrevistas con Alfonso Cuatianquiz Garza, San Francisco Tetlanohcan, 9 y 27 de octubre de 2016).

Asimismo, en la comunidad de Contlan, los cargos se rotan entre los diez barrios antiguos de la comunidad. Los barrios siempre han representado la base del único sistema de cargos vigente en la comunidad, el religioso, que funge como cabecera del municipio hoy denominado Contla de Juan Cuamatzi. Los barrios cumplen, de forma rotativa, los cargos del cabildo eclesiástico, integrados por lo que llaman la fiscalía y la cofradía (Romano y Tolteca, 2014: 67).

El último capítulo de la obra de Geovani Prisco Hernández está dedicado a los manuales de orientación para la práctica de la religiosidad popular en San Pablo del Monte, que preparó por solicitud directa de los mayordomos en función, para tener un documento que los orientara sobre la manera de ejecutar las actividades relativas al sistema de cargos religiosos de la comunidad (p. 63). Los manuales tratan, en palabras del autor, de "las celebraciones más representativas y claves dentro de la tradición sociorreligiosa de esta comunidad" (p. 65).

Para contextualizar el desarrollo de estos textos en el objetivo principal del estudio, es necesario aclarar que son guías que describen, no sólo los actos que se realizan, sino los discursos que deben acompañarlos.

El primer manual habla de la toma de juramento de las autoridades religiosas - mayordomos y fiscales - al asumir el cargo, y se dirige al sacerdote, quien suele ser una persona ajena a la comunidad, pero debe tomarles el juramento (p. 64). El segundo manual especifica las actividades preparativas en torno a la "minerva", una procesión con el Santísimo Sacramento que tiene lugar el tercer domingo de cada mes. Es organizada por una persona nombrada tlaxolacatl, quien funge como mayordomo del santísimo por un día (p. 64).

El tercer manual abarca el desposorio de San José y la Virgen de los Remedios; describe los ritos y preparativos, así como la participación de cada persona en la celebración. El cuarto es para los fiscales y mayordomos responsables del recorrido del Niño Dios por la comunidad (p. 64). El quinto habla de la fiesta conocida como altepeílhuitl y tiene el objetivo de divulgar la celebración. El sexto describe los preparativos, las procesiones y las personas que intervienen durante la Semana Santa (p. 64).

Los sistemas de cargos, la base de la religiosidad popular en San Pablo del Monte y otras comunidades nahuas de la región, son el resultado de un largo proceso de adecuación-resistencia en la lucha de supervivencia sostenida por las naciones originarias desde la llegada de los españoles. Su permanencia hasta hoy debe conceptualizarse desde esta realidad:

En el caso de las sociedades indígenas, este proceso se ha presentado como una expresión de inconformidad ante la imposición de instituciones de dominación occidental que aparecen desde la Colonia y pasaron por la conformación del Estado-nación, el corporativismo, el neoliberalismo y las crisis de los proyectos hegemónicos nacionalistas. Pese a este continuum de imposición histórica, [las] comunidades indígenas han generado estrategias de cohesión 
social que les brindan la fortaleza necesaria para dar cuenta de sus prácticas de autogobierno, entre las cuales se puede mencionar la conformación socio-espacial, que define y confiere identidad a los pueblos con sus cuerpos de fiscales, sus santos patronos, sus tierras, sus propiedades y sus recursos naturales, donde se fincan tanto los arraigos como las identidades locales y regionales (Romano y Tolteca, 2014: 26-27).

En la actualidad, la forma de reproducir la vida colectiva en general y los sistemas de cargos en particular, entre las comunidades nahuas de Tlaxcala, tiene elementos tanto propios como ajenos, pero los sistemas sobreviven con un carácter diferenciado "gracias a la reproducción hereditaria de prácticas organizativas que derivan en la defensa y la protección de un territorio" (Romano y Tolteca, 2014: 27).

Dentro de estas prácticas, el lenguaje, sea en lengua materna o en español, juega un papel fundamental. Por lo tanto, estudios como el analizado aquí dan elementos para entender la vida comunitaria desde su base misma: la forma en que las personas que componen la comunidad se comunican y se expresan al realizar los ritos religiosos. La obra de Geovani Prisco Hernández abona al estudio de los elementos culturales, como una ventana a la pluralidad que define a Tlaxcala y al país entero. $\mathbf{D}$

\section{Bibliografía}

Broda, Johanna (coord.), 2009, Religiosidad popular y cosmovisiones indígenas en la historia de México, Instituto Nacional de Antropología e Historia, México.

Lara, Luis Fernando, 2006, Curso de lexicología, El Colegio de México, México.

Romano Garrido, Ricardo y Aline Tolteca Jaime, 2014, “Emancipación y autonomía en el Altiplano Central de México”, en Ricardo Romano Garrido, Rafael Pérez-Taylor y Araceli Burguete Cal y Mayor, Territorios de otredad. Violencia, disputas y emancipación étnico-espacial en México, Universidad Autónoma de Tlaxcala/Centro de Investigaciones Interdisciplinarias sobre Desarrollo Regional/Altres CostaAmic, México, pp. 25-75.

Sánchez Mastranzo, Nazario A., 2004, “Del mito al rito: territorio simbólico de una comunidad nahua”, en Antropología, núm. 73, pp. 15-22.

\section{Entrevistas}

Alfonso Cuatianquiz Garza, San Francisco Tetlanohcan, 9 y 27 de octubre de 2016. 